\title{
Evaluation of Criteria Used in the ISP Cooperative Description of Type Strains of Streptomyces and Streptoverticillium Species
}

\author{
I. M. SZABÓ AND M. MARTON \\ Department of Microbiology, Eötvös L. University, Budapest, Hungary
}

\begin{abstract}
An analysis of the descriptions of the type or neotype strains of 457 named Streptomyces and Streptoverticillium species published in the International Journal of Systematic Bacteriology revealed that the International Streptomyces Project methods for reporting spore mass color, reverse color, and sporechain morphology need improvement. A new system of groups for the separation of strains according to their substrate mycelium color and easily determined morphological sections for preparing dichotomous keys for identification purposes are proposed.
\end{abstract}

Illustrated descriptions, in terms of standardized criteria and methods, of type or neotype strains for more than 450 Streptomyces or Streptoverticillium "species" (based on the results of the cooperative work of the International Streptomyces Project [ISP]) have been published in a series of reports in the International Journal of Systematic Bacteriology (6-8, 10). There is no doubt that these descriptions yield a firm basis for all further work in the field of taxonomy of the streptomycetes, where, as is well known, it is difficult to identify organisms and where some grouping of species is essential. Nevertheless, a critical evaluation of criteria and procedures used in the characterization of type strains, based on the examination of ISP descriptions, seems necessary before an attempt is made to group similar "species" into larger assemblages and to formulate a key based on the ISP type strains which would lead an investigator with an unknown culture to that taxon to which it belongs.

The standardized descriptive criteria and the methods used in the ISP have been partly evaluated $(2,9)$, and new diagnostic keys for the classification and identification of named taxa included in the ISP have been constructed (3).

Gottlieb and Shirling (2) used four characters (aerial mass color, sporophore morphology, spore surface, and the ability to produce melanin-like substances) for the fundamental arrangement into "primary groups" of the first 100 type or neotype strains included in the ISP. They used the formation of soluble pigments and carbon utilization patterns in forming "secondary groups" of strains that were placed together on the basis of the four prime characters; the reverse color of the substrate mycelium was not judged useful by them because of the diffi- culty in assessing or describing it. According to their opinion, the main problems were interference from the agar background, the production of melanin and other pigments, and the effect on the color of the thickness of the mycelial pad. In another publication, Shirling and Gottlieb (9) reported that the Tresner-Backus system of color wheels (13) serves remarkably well for spore color determinations and that there were few disagreements in the assignment of a culture of a given type strain on a given medium to one of the seven color series. However, although most observers agreed that the presence or absence of distinctive reverse colors is a useful characteristic, they were of the opinion that the ISP methods (12) for reporting reverse color need improvement. Cross and Goodfellow (1) emphasized that, with the Tresner-Backus color wheels, considerable practice is needed before one can easily assign a color group to the aerial mycelium of an isolate, and the various shades of gray can still cause problems. When discussing the descriptive criteria used for the characterization of streptomycetes, the color of substrate mycelium was not mentioned by them at all.

In the case of spore-chain morphology, which was defined in terms of the morphological sections of Pridham et al. (4), the results obtained in the first 5 years of collaborative research showed that the definition of section Retinaculiaperti (RA) given by Shirling and Gottlieb (5) is inadequate. Szabó and Marton $(11,12) \mathrm{em}-$ phasized that the differentiation between RA and Rectiflexibiles (RF), and in particular between RA and Spirales (S), is not clear and that section RA is unsatisfactory for a separate morphological category. On the other hand, according to Cross and Goodfellow (1), most strains 
can be easily placed in one of the ISP morphological groups (RF, RA, or S), providing the organism is grown on agar media which supports good sporulation, and only certain strains exhibiting open-spiral spore chains can cause a dilemma.

Küster (3) presented a simple diagnostic key for the classification and identification of 274 named species included in the ISP. The initial groupings were made on the basis of the color of the aerial mycelium as follows: white, gray, yellow, red, blue, and green. These were then subdivided into two groups: those with and those without a distinctive reverse pigment. But the reverse color itself was not included in the key. The reverse color of the vegetative mycelium was mentioned in the comments to the tables only if it proved to be helpful in differentiating species. Further differentiation of the groups obtained was made by using other characters in the following sequence: melanin reaction, formation of a soluble pigment, morphology of sporophores, morphology of spores, and utilization of one or more carbohydrates. In this key, three morphological categories of the aerial spore chains, designated by Küster as "straight," "flexuous," and "spiral," were used for the groupings of strains.

The present paper represents an effort to analyze quantitatively the information given in the ISP descriptions of about 450 Streptomyces and Streptoverticillium "species" and to reevaluate the taxonomic significance of some characters used by the ISP workers.

\section{Color of Substrate Mycelium (Reverse Color)}

The color of the substrate mycelium was determined in the ISP collaborating laboratories "by observing the reverse side of the growth after removal of most of the agar medium with a razor blade" (6). The cultures were assigned to one of the color groups proposed in the methods manual (5): yellow-brown (Y-b); Y-b + red (or orange); Y-b + blue or violet; Y-b + green. Also, the response of color of substrate mycelium to $\mathrm{pH}$ change was determined and included in the published descriptions. More than $95 \%$ of the studied type or neotype strains may be grouped into one of the suggested color groups. It was found by the ISP collaborators, however, that among the large number of type strains there were some organisms which showed uncommon pigmentation, or, more exactly, which are capable of producing certain rarely occurring pigments or combinations of them. Based on the ISP descriptions below, we propose a modification of the color groups which were used in the ISP studies, Table 1 shows the
TABLE 1. Distribution of 457 type or neotype strains of Streptomyces and Streptoverticillium according to their reverse-side color

\begin{tabular}{|c|c|}
\hline Suggested color groups & $\begin{array}{l}\text { No. of type or neotype } \\
\text { strains in color group }\end{array}$ \\
\hline 1. Yellow-brown (Y-b) & $327(71.6)$ \\
\hline 2. $\mathrm{Y}-\mathrm{b}+$ red & $57(12.5)$ \\
\hline 3. $Y-b+$ blue & $2(0.4)$ \\
\hline 4. $\mathrm{Y}-\mathrm{b}+$ blue $\leftrightarrow$ red & $33 \quad(7.2)$ \\
\hline 5. Y-b + blue $\leftrightarrow$ green & $2(0.4)$ \\
\hline 6. $\mathrm{Y}-\mathrm{b}+$ green & $16 \quad(3.5)$ \\
\hline 7. $\mathrm{Y}-\mathrm{b}+$ green $\leftrightarrow$ red & $3 \quad(0.7)$ \\
\hline 8. $\mathrm{Y}-\mathrm{b}+\mathrm{red}+$ green & $(0.9)$ \\
\hline 9. Y-b + red + blue & $(0.4)$ \\
\hline 10. $\mathrm{Y}-\mathrm{b}+$ blue + green & $3 \quad(0.7)$ \\
\hline $\begin{array}{l}\text { 11. } \\
\text { red }\end{array}$ & $1 \quad(0.2)$ \\
\hline Questionable & $7 \quad(1.5)$ \\
\hline
\end{tabular}

${ }^{a}$ Numbers in parentheses are percentages of the 457 strains studied.

distribution of 457 type or neotype strains of Streptomyces and Streptoverticillium according to the color groups proposed by us, which are as follows.

1. Yellow-brown (Y-b): The color of the mycelium exhibits different hues of yellow and brown in all diagnostic culture media and in all periods of growth; these yellow-brown colors may be shaded by gray in all degrees from almost colorless light gray through dirty white to black.

2. Y-b + red: On at least one diagnostic culture medium and in a certain period of growth, the mycelium produces red or pink endopigments to such an extent that both the yellowbrown ground color and gray shade are entirely obscured, and the mycelium becomes red. The red endopigments are not $\mathrm{pH}$ sensitive or they may change in the case of a few strains from red or pink to the yellow-brown ground color either with the addition of $0.05 \mathrm{~N} \mathrm{HCl}$ or, more rarely, with the addition of $0.05 \mathrm{~N} \mathrm{NaOH}$.

3. Y-b + blue: Similar to Y-b + red (no. 2) above, except that the endopigment is blue. This pigment is not a $\mathrm{pH}$ indicator.

4. $\mathrm{Y}-\mathrm{b}+$ blue $\leftrightarrow$ red: Similar to $\mathrm{Y}-\mathrm{b}+$ red (no. 2) above, except that the reverse mycelium pigment is a $\mathrm{pH}$ indicator changing from blue or blue-violet to red-violet or red.

5. Y-b + blue $\leftrightarrow$ green: Similar to $\mathrm{Y}-\mathrm{b}+$ red (no. 2) above, except that the reverse mycelium pigment is a pH indicator changing from blue, grayish purple, or violet to green or deep green.

6. Y-b + green: Similar to $Y-b+$ red (no. 2) above, except that the reverse mycelium pigment is green. This endopigment is not a $\mathrm{pH}$ indicator.

7. $\mathrm{Y}-\mathrm{b}+$ green $\leftrightarrow$ red: Similar to $\mathrm{Y}-\mathrm{b}+$ red 
(no. 2) above, except that the reverse mycelium pigment is a $\mathrm{pH}$ indicator changing from green, olive, bluish green or grayish olive to red, pink, or reddish or purplish brown.

8. $Y-b+$ red + green: Two different, a red and a green, distinctive pigments can cause colorization in the substrate mycelium depending on the composition of the diagnostic medium employed. Neither of them is a $\mathrm{pH}$ indicator.

9. $Y-b+$ red + blue: Similar to $Y-b+$ red + green (no. 8) above, except that the yellowbrown ground color of the substrate mycelium may be modified to red and/or to blue on the diagnostic media. These pigments are not $\mathrm{pH}$ sensitive.

10. $Y-b+$ blue + green: Similar to $Y-b+$ red + green (no. 8) above, except that the color of substrate mycelium may be modified to blue and/or to green on the diagnostic media. These pigments are not $\mathrm{pH}$ sensitive.

11. $\mathrm{Y}-\mathrm{b}+$ green + blue $\leftrightarrow$ red: Similar to $\mathrm{Y}-\mathrm{b}$ + red + green (no. 8) above, except that the color of substrate mycelium may be modified to green and/or to red, violet, or blue depending on the composition and $\mathrm{pH}$ of the media. The green pigment is not $\mathrm{pH}$ sensitive.

The data presented in Table 1 show that distinctive pigments are not formed in the substrate mycelium of the majority (more than $71 \%$ ) of the type or neotype strains described by the ISP workers. These strains are characterized in the ISP descriptions as organisms in which the reverse side of the colony is colorless, light or pale yellow, yellowish gray, olive brown, yellowish brown, etc. Within this range, differences in value as well as hue are not reliably constant with species and consequently are not useful for species differentiation.

Approximately $12 \%$ (57) of the strains produce red or pink endopigments which are either not $\mathrm{pH}$ sensitive or change from red to the yellow-brown ground color. The red substrate mycelium pigment of 33 strains is a $\mathrm{pH}$ indicator, changing from blue or blue-violet to violet, red-violet, or red. The green distinctive pigment in the substrate mycelium of 16 strains is not $\mathrm{pH}$ sensitive. Only two strains are characterized in the ISP descriptions by a blue reverse color which is not a $\mathrm{pH}$ indicator.

The number of strains characterized by certain combiations of two distinctive endopigments in the substrate mycelium is relatively low (see Table 1), but the color groups based on these rarely occurring organisms are useful for species differentiation. The production of distinctive pigments on the diagnostic media used is questionable in the case of seven of the ISP strains.

\section{Color of the Surface of the Aerial Mycelium After Sporulation}

The Tresner-Backus color wheels were used by the ISP workers to determine the color series (Red, Yellow, Green, Blue, Violet, Gray, or White) by comparing mature spore-mass color on all appropriate media with the color tabs of the color wheels. Aerial mycelium suitable for color determination was not observed in the case of 31 strains.

According to the data given in the ISP descriptions from among the 426 classified strains, $232(54 \%)$ fall within the range delineated by one wheel whereas 194 strains (46\%) fall into 2, 3, and 4 different color series, respectively, when examined on different media (Table 2). This shows that the strains of Streptomyces and Streptoverticillium frequently produce spore-mass colors identical with or similar to the color tabs of different color wheels.

Consequently, the same strain can belong to different color series. Besides, it is a fact that not only is considerable practice needed to recognize the color groups even with the aid of the color wheels, but also a precise color identification is, quite often, very difficult owing to the interference from the colored substrate mycelium and to the dependence of the aerial-mass color on the thickness and density of the spore mass. Although the Tresner-Backus system of color wheels serves relatively well, the results of the above analysis of the ISP descriptions clearly show that a certain modification of the color series offered by these authors is necessary if they are to be used for classification and identification purposes.

Table 2 presents the distribution of 457 type or neotype strains of Streptomyces and Streptoverticillium species according to their aerialmass color. As can be seen, the Violet series is probably not useful for species differentiation.

Certain strains which are capable of producing red or reddish gray spores can also produce, at the same time, a violet aerial-mass color depending on the composition of the medium used. It is a fact that many of the strains placed by the ISP workers in different color series (Red, Yellow, Gray, etc.) can produce, on certain media, aerial-mass colors identical with or similar to the color tabs of the White series. It is questionable, however, that this great number of unexpected combinations resulted only from errors in color determinations, for "Some observers recorded the surface color without regard to the presence or absence of a good mat of 
TABLE 2. Distribution of 457 type or neotype strains of Streptomyces and Streptoverticillium according to their aerial-mass color determined with the aid of the Tresner-Backus system of color wheels

\begin{tabular}{|c|c|c|c|c|c|c|c|c|}
\hline \multicolumn{8}{|c|}{ The aerial mass colors fall: } & \multirow{3}{*}{\begin{tabular}{|c|}
$\begin{array}{c}\text { Aerial myce- } \\
\text { lium poorly } \\
\text { developed or } \\
\text { absent on all } \\
\text { media }\end{array}$ \\
No. of strains
\end{tabular}} \\
\hline \multicolumn{2}{|c|}{$\begin{array}{l}\text { Within the same color } \\
\text { series on all media }\end{array}$} & \multicolumn{2}{|c|}{$\begin{array}{l}\text { Into } 2 \text { different } \\
\text { color series }\end{array}$} & \multicolumn{2}{|c|}{$\begin{array}{l}\text { Into } 3 \text { different } \\
\text { color series }\end{array}$} & \multicolumn{2}{|c|}{$\begin{array}{l}\text { Into } 4 \text { different } \\
\text { color series }\end{array}$} & \\
\hline $\begin{array}{l}\text { Color } \\
\text { group }\end{array}$ & $\begin{array}{c}\text { No. of } \\
\text { strains }\end{array}$ & $\begin{array}{l}\text { Color } \\
\text { group }\end{array}$ & $\begin{array}{c}\text { No. of } \\
\text { strains }\end{array}$ & Color group & $\begin{array}{l}\text { No. of } \\
\text { strains }\end{array}$ & Color group & $\begin{array}{l}\text { No. of } \\
\text { strains }\end{array}$ & \\
\hline $\begin{array}{l}\text { W } \\
\mathrm{R} \\
\mathrm{G} \\
\mathrm{Y} \\
\mathrm{Gr} \\
\mathrm{B}\end{array}$ & $\begin{array}{r}11 \\
53 \\
113 \\
37 \\
6 \\
12\end{array}$ & $\begin{array}{l}V+G \\
W+G \\
W+B \\
W+R \\
W+Y \\
Y+B \\
Y+G r \\
R+G \\
R+V \\
R+Y \\
G+G r \\
G+Y \\
G+B \\
G r+B\end{array}$ & $\begin{array}{r}1 \\
13 \\
4 \\
16 \\
27 \\
1 \\
2 \\
42 \\
5 \\
17 \\
5 \\
17 \\
4 \\
2\end{array}$ & $\begin{array}{l}\mathrm{W}+\mathrm{G}+\mathrm{Y} \\
\mathrm{W}+\mathrm{R}+\mathrm{G} \\
\mathrm{W}+\mathrm{R}+\mathrm{Y} \\
\mathrm{W}+\mathrm{G}+\mathrm{Gr} \\
\mathrm{W}+\mathrm{R}+\mathrm{V} \\
\mathrm{W}+\mathrm{G}+\mathrm{B} \\
\mathrm{W}+\mathrm{Y}+\mathrm{Gr} \\
\mathrm{Y}+\mathrm{Gr}+\mathrm{B} \\
\mathrm{R}+\mathrm{G}+\mathrm{Y} \\
\mathrm{R}+\mathrm{V}+\mathrm{G} \\
\mathrm{R}+\mathrm{G}+\mathrm{Gr} \\
\mathrm{R}+\mathrm{G}+\mathrm{B} \\
\mathrm{G}+\mathrm{Gr}+\mathrm{B}\end{array}$ & $\begin{array}{l}7 \\
9 \\
6 \\
1 \\
1 \\
3 \\
2 \\
1 \\
2 \\
1 \\
1 \\
1 \\
1\end{array}$ & $\begin{array}{l}\mathrm{R}+\mathrm{G}+\mathrm{Y}+\mathrm{B} \\
\mathrm{Y}+\mathrm{G}+\mathrm{Gr}+\mathrm{R}\end{array}$ & $\begin{array}{l}1 \\
1\end{array}$ & 31 \\
\hline Totals & $232(50.8)^{b}$ & & $156(34.1)$ & & $36(7.9)$ & & $2(0.4)$ & $31(6.8)$ \\
\hline
\end{tabular}

"Abbreviations: W, White; R, red; G, gray; Y, yellow; Gr, green; B, blue; V, violet.

${ }^{b}$ Figures in parentheses are percentages.

sporulating aerial mycelium" (9). Certain strains characterized by yellow, gray, etc. spore-mass colors may produce, on certain media, white aerial mycelium containing a large number of spore-bearing hyphae.

It seems advisable to place into the Gray series only the strains which produce gray aerial mass without any detectable reddish or purplish shade, and, vice versa, strains with pale purple, grayish purple, etc. spore colors into the Red series. Strains of Streptomyces belonging to the "griseus" group characterized by many workers with yellow or yellowish green aerial mycelium were frequently placed by the ISP collaborators into the Gray series. On the other hand, although the number of the ISP strains which can produce blue or green aerial mycelium is not too high, the majority of these organisms fall into two or more different color series (Table 2), and the same strain can, not rarely, produce a blue- or green-colored aerial mass depending on the nature of the medium used. All of these facts clearly show not only that the "aerial-mass color" does not belong to those characters which are easy to determine, but also that caution is necessary if it is to be used in preparing working keys for the classification and identification of streptomycetes.

\section{Micromorphology of the Spore-Bearing Hyphae}

The form of the spore-bearing hyphae and spore chains is described in terms of the mor- phological groups of Pridham et al. as modified by Baldacci (see reference 5). Fifteen strains, from among the 457 studied, were not classified because they failed to produce aerial mycelium adequate for morphological observations.

Table 3 shows the distribution of the remaining 442 strains according to their spore-chain morphology. Approximately 134 strains (30\%) produce straight and/or flexible (Rectiflexibiles) spore-bearing aerial hyphae. In the case of 80 strains ( 15 of $S+R A+R+F$, and 65 of $S$ + RA), the observers found that the spore chains appeared to be intermediate between spirals and morphological forms related to the section Retinaculiaperti, or, more frequently, spore-bearing hyphae characteristic of both sections were present in the same culture at the same time. These findings corroborate our earlier statement $(11,12)$ that, although in certain cases it may be relatively easy to distinguish between RA and Spirales, in general the production of the more or less irregularly spiraled sporophores (RA) cannot be considered, in contrast to the more or less regularly spiraled ones, as a "distinguishing feature" which would be available for preparing dichotomous keys for identification purposes. All of the morphological forms, including spore chains forming open loops, greatly extended, irregular, poorly defined spirals, and spirals of regular turns, are considered by us as belonging to the section Spirales. Table 3 presents the distribution of the ISP strains according to the more easily 
TABLE 3. Distribution of 442 type or neotype strains of Streptomyces and Streptoverticillium according to the morphology of the sporulating aerial mycelium

\begin{tabular}{|c|c|c|c|}
\hline $\begin{array}{c}\text { Proposed morphological sec- } \\
\text { tions }\end{array}$ & No. of strains ${ }^{n}$ & $\begin{array}{l}\text { Morphological groups of Pridham et } \\
\text { al. as modified by Baldacci }{ }^{b}\end{array}$ & No. of strains ${ }^{a}$ \\
\hline Rectiflexibiles & $134(30.3)$ & $\begin{array}{l}\mathrm{R} \\
\mathrm{F}\end{array}$ & $134(30.3)$ \\
\hline Spirales & $265(60.0)$ & $\begin{array}{l}S \\
R A \\
S+R A+R+F \\
S+R+F \\
S+R A \\
R A+R+F\end{array}$ & $\begin{array}{rr}132 & (29.9) \\
16 & (3.6) \\
15 & (3.4) \\
18 & (4.1) \\
65 & (14.7) \\
19 & (4.3)\end{array}$ \\
\hline Verticillate-Rectiflexibiles & $32 \quad(7.2)$ & $\begin{array}{l}\text { Monoverticillus } \\
\text { Biverticillus }\end{array}$ & $(7.2)$ \\
\hline Verticillate-Spirales & $3 \quad(0.7)$ & $\begin{array}{l}\text { Monoverticillus-Spira } \\
\text { Biverticillus-Spira }\end{array}$ & $(0.7)$ \\
\hline Questionable & $8 \quad(1.8)$ & Questionable & $(1.8)$ \\
\hline
\end{tabular}

"Figures in parentheses are percentages.

${ }^{b}$ Abbreviations: R, Rectus; F, Flexibilis; S, Spira; RA, Retinaculum-Apertum.

distinguished four morphological sections which we are suggesting here for the characterization of streptomycetes. About $60 \%$ of the strains belong to the Spirales section, and about $7.2 \%$ belong to the section VerticillateRectiflexibiles.

\section{Surface Ornamentation of the Spores}

Spiny or hairy ornamentations on the spore surface and smooth spores with no surface ornamentation (as observed with the electron microscope) are generally considered as stable and readily distinguishable characteristics. Table 4 shows that, from among the 436 strains classified in this respect by the ISP observers, 36 strains fell into two or three categories, 320 were smooth, 61 were spiny, 10 were hairy, and only 7 were warty. Although the results of the ISP studies clearly showed that the type of surface ornamentation is, in general, justly assessed as a reliable and constant characteristic, whether all strains of a species have the same kind of spore surface ornamentation needs further study. Our studies (11) on the variability of Streptomyces finlayi showed that, whereas some strains of this species produce both hairy and smooth spores, others produce only smooth spores.

\section{Melanin Production}

Melanin pigment was produced on peptoneyeast-iron agar by 177 and on tyrosine agar by only 83 of the 457 ISP strains. In the case of 12 and 31 strains on peptone-yeast-iron agar and tyrosine agar, respectively, melanin production was doubtful. Melanin production on tyrosine agar was not determined for 27 strains. The observations of the ISP collaborators on the presence or absence of melanoid pigments in the ISP media are, in general, in good agreement. It is, however, another question whether melanin production is or is not a stable feature in relation to the population of a species.

\section{Utilization of Carbohydrates and Other Compounds}

The utilization of carbohydrates and of other carbon sources has been recommended by many authors as an aid to species differentiation. Table 5 shows the results of ISP studies concerning the utilization capabilities of the 457 ISP strains in relation to nine carbon sources. The utilization of sucrose is doubtful in the case of $85(18.7 \%)$ strains. About $10 \%$ of the strains showed only slightly better growth on arabi-

TABLE 4. Distribution of 436 type or neotype strains of Streptomyces and Streptoverticillium according to the spore-surface morphology

\begin{tabular}{lrr}
\hline \multicolumn{1}{c}{ Spore-surface morphology } & \multicolumn{2}{c}{ No. of strains ${ }^{a}$} \\
\hline Smooth & 320 & $(73.4)$ \\
Warty & 7 & $(1.6)$ \\
Spiny & 61 & $(14.0)$ \\
Hairy & 10 & $(2.3)$ \\
& & \\
Smooth + warty & 11 & $(2.5)$ \\
Smooth + spiny & 10 & $(2.3)$ \\
Smooth + hairy & 1 & $(0.2)$ \\
Warty + spiny & 4 & $(0.9)$ \\
Spiny + hairy & 8 & $(1.8)$ \\
& 2 & $(0.5)$ \\
Smooth + warty + spiny & 2 & $(0.5)$ \\
\hline
\end{tabular}

"Figures in parentheses are percentages. 
TABLE 5. Utilization of carbon compounds as sole carbon sources

\begin{tabular}{lcccc}
\hline Substrate & No. of strains & $\begin{array}{c}\text { No. of utilizing } \\
\text { strains }^{b}\end{array}$ & $\begin{array}{c}\text { No. of non-utilizing } \\
\text { strains }^{b}\end{array}$ & $\begin{array}{c}\text { No. of strains with } \\
\text { doubtful growth }^{b}\end{array}$ \\
\hline Glucose & 455 & $451(99.1)$ & $2(0.4)$ & 2 \\
Arabinose & 452 & $324(71.7)$ & $85(18.8)$ & $43(9.5)$ \\
Xylose & 455 & $345(75.8)$ & $64(14.1)$ & $46(10.1)$ \\
Fructose & 454 & $375(82.6)$ & $22(4.9)$ & $57(12.6)$ \\
Rhamnose & 454 & $240(52.9)$ & $176(38.8)$ & $38(8.4)$ \\
Sucrose & 455 & $160(35.2)$ & $210(46.2)$ & $85(18.7)$ \\
Raffinose & 454 & $149(32.8)$ & $242(53.3)$ & $63(13.9)$ \\
Inositol & 455 & $241(53.0)$ & $157(34.5)$ & $57(12.5)$ \\
Mannitol & 455 & $319(70.1)$ & $110(24.2)$ & 26 \\
\hline
\end{tabular}

${ }^{a}$ Data were not reported for all of the 457 strains included in these tests.

${ }^{b}$ Figures in parentheses are percentages.

nose, xylose, fructose, rhamnose, raffinose, or inositol than on the basal medium without carbon and significantly less growth than with glucose. Unfortunately, this large number of doubtful tests can considerably hinder our efforts to construct dichotomous keys which include the utilization of carbon sources for the identification of the named taxa included in the ISP. Furthermore, strain variability within species and with respect to carbohydrate utilization must be taken into account in any attempt to construct working keys for the identification of named species.

\section{REPRINT REQUESTS}

Address reprint requests to: I. Szabó, Department of Microbiology, Eötvös L. University, Budapest VIII. Muzeum krt. 4/a. Hungary.

\section{LITERATURE CITED}

1. Cross, T., and M. Goodfellow. 1973. Taxonomy and classification of the actinomycetes, p. 11-112. In G. Sykes, and F. A. Skinner (ed.), Actinomycetales: characteristics and practical importance. Academic Press Inc., New York.

2. Gottlieb, D., and E. B. Shirling. 1970. An analysis of species groups among Streptomyces, p. 67-77. In $\mathrm{H}$. Prauser (ed.), The Actinomycetales. VEB G. Fischer Verlag, Jena.

3. Küster, E. 1972. Simple working key for the classification and identification of named taxa included in the International Streptomyces Project. Int. J. Syst. Bacteriol. 22:139-148.
4. Pridham, T. G., C. W. Hesseltine, and R. G. Benedict. 1958. A guide for the classification of streptomycetes according to selected groups: placement of strains in morphological sections. Appl. Microbiol. 6:52-79.

5. Shirling, E. B., and D. Gottlieb. 1966. Methods for characterization of Streptomyces species. Int. J. Syst. Bacteriol. 16:313-340.

6. Shirling, E. B., and D. Gottlieb. 1968. Cooperative description of type cultures of Streptomyces. II. Species descriptions from first study. Int. J. Syst. Bacteriol. 18:69-189.

7. Shirling, E. B., and D. Gottlieb. 1968. Cooperative description of type cultures of Streptomyces. III. Additional species descriptions from first and second studies. Int. J. Syst. Bacteriol. 18:279-392.

8. Shirling, E. B., and D. Gottlieb. 1969. Cooperative description of type cultures of Streptomyces. IV. Species descriptions from the second, third and fourth studies. Int. J. Syst. Bacteriol. 19:391-512.

9. Shirling, E. B., and D. Gottlieb. 1970. Report of the International Streptomyces Project. Five years of collaborative research, p. 79-89. In $\mathrm{H}$. Prauser (ed.), The Actinomycetales. VEB G. Fischer Verlag, Jena.

10. Shirling, E. B., and D. Gottlieb. 1972. Cooperative description of type strains of Streptomyces. V. Additional descriptions. Int. J. Syst. Bacteriol. 22:265394.

11. Szabó, I. M. 1974. Microbial communities in a forestrendzina ecosystem. The pattern of microbial communities. Akad. Kiadó, Budapest.

12. Szabo, I., and M. Marton. 1964. Comments on the first results of the international cooperative work on criteria used in characterization of streptomycetes. Int. Bull. Bacteriol. Nomencl. Taxon. 14:17-38.

13. Tresner, H. D., and E. J. Backus. 1963. System of color wheels for streptomycete taxonomy. Appl. Microbiol. 11:335-338. 